\title{
The role of retinoic acid in hepatic lipid homeostasis defined by genomic binding and transcriptome profiling
}

Yuqi He ${ }^{1}$, Lei Gong ${ }^{2}$, Yaping Fang ${ }^{3}$, Qi Zhan ${ }^{4}$, Hui-Xin Liu', Yanliu Lu', Grace L Guo ${ }^{5}$, Lois Lehman-McKeeman², Jianwen Fang ${ }^{6}$ and Yu-Jui Yvonne Wan ${ }^{1 *}$

\begin{abstract}
Background: The eyes and skin are obvious retinoid target organs. Vitamin A deficiency causes night blindness and retinoids are widely used to treat acne and psoriasis. However, more than $90 \%$ of total body retinol is stored in liver stellate cells. In addition, hepatocytes produce the largest amount of retinol binding protein and cellular retinoic acid binding protein to mobilize retinol from the hepatic storage pool and deliver retinol to its receptors, respectively. Furthermore, hepatocytes express the highest amount of retinoid $x$ receptor alpha (RXRa) among all the cell types. Surprisingly, the function of endogenous retinoids in the liver has received very little attention.

Results: Based on the data generated from chromatin immunoprecipitation followed by sequencing, the global DNA binding of transcription factors including retinoid $x$ receptor a $(R X R a)$ along with its partners i.e. retinoic acid receptor a $(R A R a)$, pregnane $x$ receptor $(P X R)$, liver $x$ receptor $(L X R)$, farnesoid $x$ receptor (FXR), and peroxisome proliferator-activated receptor a (PPARa) has been established. Based on the binding, functional annotation illustrated the role of those receptors in regulating hepatic lipid homeostasis. To correlate the DNA binding data with gene expression data, the expression patterns of 576 genes that regulate lipid homeostasis were studied in wild type and liver RXRa-null mice treated with and without RA. The data showed that RA treatment and RXRa-deficiency had opposite effects in regulating lipid homeostasis. A subset of genes (114), which could clearly differentiate the effect of ligand treatment and receptor deficiency, were selected for further functional analysis. The expression data suggested that RA treatment could produce unsaturated fatty acids and induce triglyceride breakdown, bile acid secretion, lipolysis, and retinoids elimination. In contrast, RXRa deficiency might induce the synthesis of saturated fatty acids, triglyceride, cholesterol, bile acids, and retinoids. In addition, DNA binding data indicated extensive cross-talk among RARa, PXR, LXR, FXR, and PPARa in regulating those RA/RXRa-dependent gene expression levels. Moreover, RA reduced serum cholesterol, triglyceride, and bile acid levels in mice.
\end{abstract}

Conclusions: We have characterized the role of hepatic RA for the first time. Hepatic RA mediated through RXRa and its partners regulates lipid homeostasis.

Keywords: Nuclear receptor, Retinoids $x$ receptor, Retinoic acid receptor, Farnesnoid $x$ receptor, Peroxisomal proliferator-activated receptor a, Liver $\mathrm{x}$ receptor, Pregnane $\mathrm{x}$ receptor, Chromatin immunoprecipitation, Sequencing, Microarray

\footnotetext{
* Correspondence: yjywan@ucdavis.edu

${ }^{1}$ Department of Medical Pathology and Laboratory Medicine, University of California, Davis Health Systems, Sacramento 95817, CA, USA

Full list of author information is available at the end of the article
} 


\section{Background}

The eyes and skin are obvious retinoid target organs. Vitamin A deficiency causes night blindness and retinoids are widely used to treat acne and psoriasis. However, more than $90 \%$ of total body retinol (retinylpalmitate, the storage form) is stored in liver stellate cells [1]. In addition, hepatocytes produce the largest amount of retinol binding protein and cellular retinoic acid binding protein to mobilize retinol from the hepatic storage pool and deliver retinol to its receptors, respectively [2]. Furthermore, hepatocytes express the highest amount of retinoid $x$ receptor alpha $(\mathrm{RXR} \alpha)$ among all the cell types. Surprisingly, the function of endogenous retinoids in the liver has received very little attention. Thus, the current study aims to identify the bona fide RXR $\alpha$ and RAR $\alpha$ targets in the liver.

The broad and complicated roles of retinoids can be explained by the presence of multiple receptors for retinoic acid (RA), the biological active form of retinol. The receptors for RA are retinoic acid receptor (RAR) as well as retinoid $x$ receptor (RXR) [2]. In addition, RXR is essential for many other receptors to function. These receptors for RA belong to a nuclear receptor family whose members are transcriptional factors. Thus, RA exerts its biological effects by regulating gene expression. RXR is unique in that it not only forms homodimers, but also dimerizes with other nuclear receptors, which include receptors for fatty acids (peroxisomal proliferator-activated receptors, PPARs), bile acids (farnesoid $\mathrm{x}$ receptor, FXR), oxysterols (liver $\mathrm{x}$ receptor, LXR), xenobiotics (pregnane $\mathrm{x}$ receptor, PXR, and constitutive androstane receptor, CAR), vitamin D (vitamin D receptor, VDR), and RA (RAR). Hence, most RXR partners participate in regulating lipid homeostasis. Within these heterodimers, RXR can be either a permissive or a silent partner. When RXR serves as a silent partner, the heterodimer does not respond to RA. When it is a permissive (active) partner, RA and the ligand for the heterodimeric partner can both activate the heterodimer. For example, RXR is a permissive partner for PPAR [3]. Similarly, heterodimeric complexes of RXR with LXR [4] or FXR [5] also retain RA responsiveness. Furthermore, retinoids also activate PXR, VDR, and CAR thus are able to thus regulate xenobiotic metabolism and potentially their own oxidation [6-8]. Since most of these receptors are abundantly expressed in the liver, the endogenous RA may regulate many hepatic nuclear receptor-mediated pathways. Therefore, the role of RA in the liver is unpredictable. In order to understand the endogenous function of RA and its receptors, it is crucial to identify RA receptor targets (genes and pathways) genome-wide.

$\mathrm{RXR} \alpha$ is highly expressed in the liver [9]. Liver specific $\mathrm{RXR} \alpha$-deficient mice have increased serum triglyceride and cholesterol levels $[10,11]$. In addition, lack of hepatic RXR $\alpha$ increases sensitivity to alcohol- and non-alcohol-induced steatosis and steatohepatitis [12,13]. Besides regulating lipid metabolism, hepatocyte $\mathrm{RXR} \alpha$ also controls xenobiotic [14-16], carbohydrate [17], and amino acid metabolism [17]. These findings indicate that $R X R \alpha$-mediated signaling has a huge impact on maintaining liver health and in regulating many disease processes.

To understand the global roles of RXR $\alpha$ and RAR $\alpha$ at the genomic level, chromatin immunoprecipitation using anti-RXR $\alpha$ and -RAR $\alpha$ antibodies followed by sequencing (ChIP-seq) was performed. Since RXR $\alpha$ is an essential partner for other nuclear receptors, we compared ChIP-seq data to RXR $\alpha$ binding locations with locations from previous studies for PXR [18], LXR [19], FXR [20], and PPAR $\alpha$ [19]. Meanwhile, the expression levels of the genes responsible for lipid homeostasis were studied in wild type and hepatic RXR $\alpha$-deficient mouse livers. Both genome-wide DNA-binding and hepatic gene expression data were used to define the role of RA in the liver. Our data uncovered the unknown function of retinoic acid and RXR vs. RAR in the liver. Using different approaches, we showed for the first time that retinoic acid-activated RXR $\alpha$ and RAR $\alpha$ have distinct effects. Moreover, the action of retinoic acid in the liver is to regulate lipid homeostasis specifically by reducing serum cholesterol, triglyceride and bile acid levels. The data provided may lead to future development of synthetic retinoid that can target metabolic syndrome or other types of lipid-associated health issues.

\section{Results}

Genome-wide binding of RXRa, RARa, PXR, LXR, FXR, and PPARa in mouse livers

To understand the global roles of RXR $\alpha$ and RAR $\alpha$ at the hepatic genome level, ChIP-seq was performed using anti-RXR $\alpha$ and -RAR $\alpha$ antibodies. Single read sequencing yielded 18 and 32 million uniquely mapped reads for RXR $\alpha$ and RAR $\alpha$, respectively. After filtering by including peak scores that were greater than 20 and distance within $10 \mathrm{~kb}$ from the transcriptional start site, 17,973 peaks were detected for $\mathrm{RXR} \alpha$ and 18,697 peaks for RAR $\alpha$. Since RXR $\alpha$ is an essential partner for other nuclear receptors, we compared ChIP-seq data of RXR $\alpha$ with those of PXR [18], LXR [19], FXR [20], and PPAR $\alpha$ [19]. Our data showed that the numbers of peaks, which were commonly bound by RXR $\alpha$ and other nuclear receptors, were 6,577 for RAR $\alpha$, followed by 5,154 for PPAR $\alpha, 2,846$ for FXR, 1,190 for LXR, and 868 for PXR in the mouse liver genome. RAR $\alpha$ had less than $50 \%$ overlapping bindings with $\operatorname{RXR} \alpha$ while PPAR $\alpha, F X R$, LXR, and PXR had over 85\% overlapping bindings with RXR $\alpha$ (Figure 1A). These findings suggest that $R X R \alpha$ is indispensable for the function of PPAR $\alpha, F X R$, LXR and PXR in the mouse liver. In contrast, RAR $\alpha$ may work in the absence of RXR $\alpha$. More than 4000 of RAR $\alpha$ binding genes were bound by $\mathrm{RXR} \alpha$, and occupied $56 \%$ of total RXR $\alpha$ bindings, followed by PPAR $\alpha$ (43\%), FXR (25\%), 


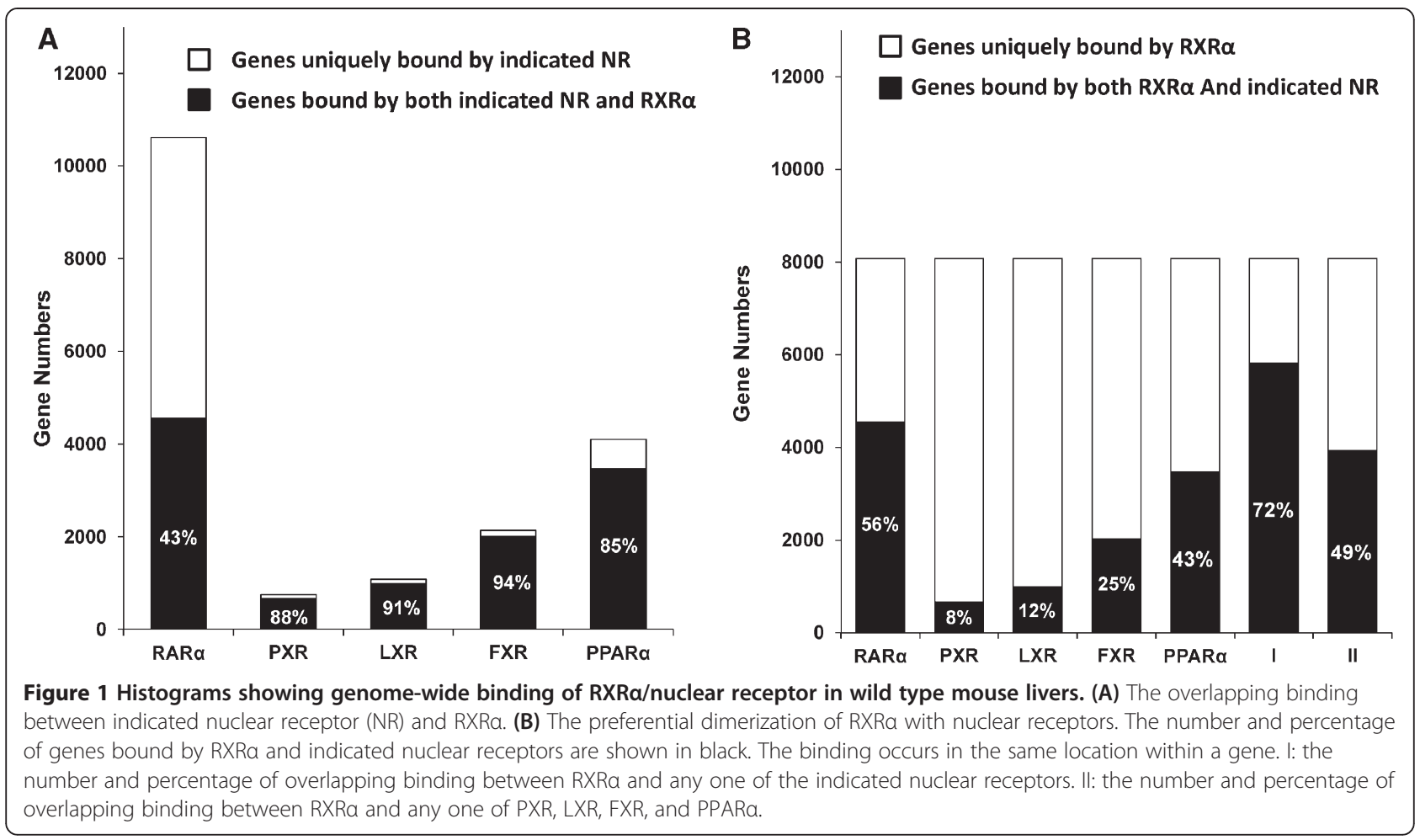

LXR (12\%), and PXR (8\%). The well-known lipid regulators including PPAR $\alpha, F X R$, LXR, and PXR bound to almost $50 \%$ of RXR $\alpha$-bound regions suggesting the extensive role of $\mathrm{RXR} \alpha$ in regulating lipids.

Cluster and principal component analysis (PCA) were performed using the binding data. Overlapping bindings between RXR $\alpha$ and RAR $\alpha$, PPAR $\alpha$, FXR, LXR, and PXR were analyzed. According to the length of the vertical branches (Figure 2A), LXR and PXR were clustered into one basic group. FXR was clustered into a subgroup with LXR and PXR. PPAR, PXR, LXR, and FXR were classified into another group. However, RAR $\alpha$ was distant from the others. The same datasets were subjected to PCA analysis. After dimension deduction, two components were picked to describe the global properties of the samples. The two-dimension score plot showed that LXR and PXR had the shortest distance, implying their properties on the genome-wide binding level were most
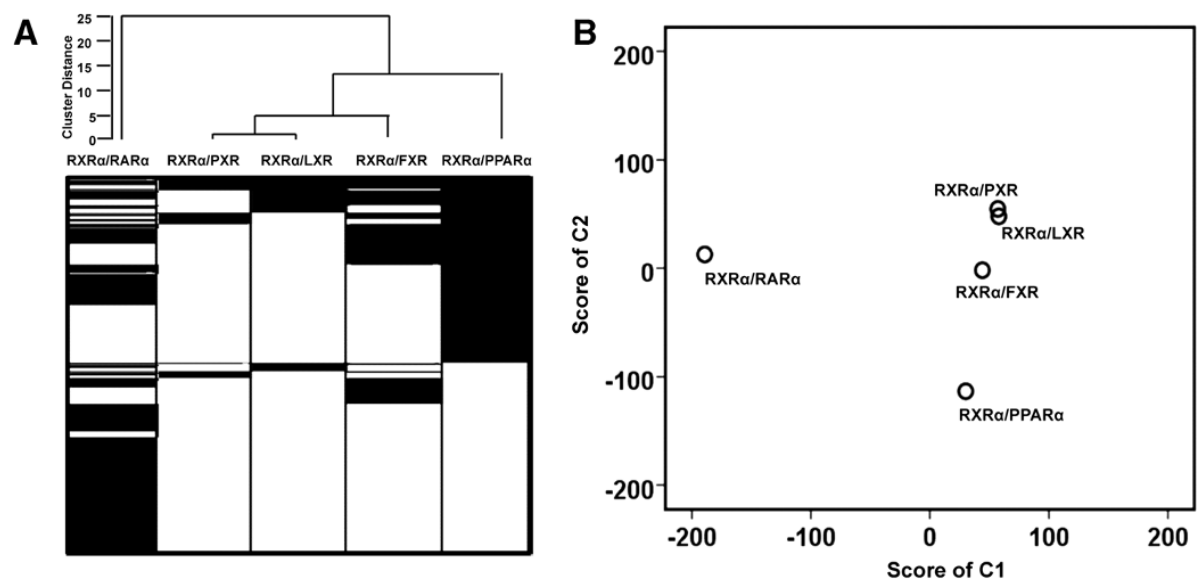

Figure 2 Genome-wide profiling of RXRa/nuclear receptor binding sites. (A) A dendogram was generated by cluster analysis to show RXRa/ nuclear receptor (NR) binding sites. Each horizontal line represents a binding site. White regions indicate there is no peak called. The lengths of the vertical lines represent the distance between the sets of target genes for the nuclear receptors when clustered. (B) A score plot of PCA analysis for RXRa/nuclear receptors binding sites. Scores of component 1 and 2 were obtained from the linear combination of all the nuclear receptors binding sites. 
similar (Figure 2B). The distance between FXR and LXR/ PXR was shorter than the distances between other receptors and LXR/PXR. RAR $\alpha$ was far from all other nuclear receptors. Thus, the information generated from the PCA and cluster analysis was consistent. The difference among the binding profiles of PXR, LXR, FXR, and PPAR $\alpha$ were described by component 2 while the difference between the binding profile of RAR $\alpha$ and those four nuclear receptors were described by component 1 in the PCA.

\section{Function analysis of the genes that have overlapping} binding sites between RXRa and each of RARa, PXR, LXR, FXR, and PPARa

To understand the potential biological role of genes likely to be targeted by RXR $\alpha$-heterodimers, DAVID functional annotation was performed. The top ten processes for each of the heterodimers formed by RXR $\alpha$ and other nuclear receptors were investigated in this study (Table 1). Although common pathways among these heterodimers, such as carboxylic acid catabolic process, organic acid catabolic process, and oxidation reduction, appeared in the top 10 pathways, the heterodimers still have their unique biological functions. RXR $\alpha-R A R \alpha$ uniquely regulated protein transport, localization, and RNA processing. The heterodimers of RXR $\alpha$ and PXR, LXR, FXR, and PPAR $\alpha$ have a great impact on various lipid processing pathways. For example, RXR $\alpha-P P A R \alpha$ and RXR $\alpha-L X R$ tend to bind to the genes involved in acylglycerol, glycerol ether, and neutral lipid metabolic processes, which are fatty acid derived. In addition, RXR $\alpha$-PPAR $\alpha$ distinctly binds to the genes that are involved in fatty acid metabolic processes, and RXR $\alpha$-LXR is more prone to bind to the genes that participate in steroid metabolic process. In addition to steroid metabolic process, RXR $\alpha$-FXR also tends to bind to genes that dictate lipid

Table 1 Common and unique biological function of genes bound by RXRa coupled with RARa, PXR, LXR, FXR and PPARa

\begin{tabular}{|c|c|c|c|c|c|}
\hline Pathways & RARa & PXR & LXR & FXR & PPARa \\
\hline Acylglycerol metabolic process & & & $1.9 \mathrm{E}-07$ & & $3.8 \mathrm{E}-10$ \\
\hline Neutral lipid metabolic process & & & 2.7E-07 & & $9.4 \mathrm{E}-10$ \\
\hline Glycerol ether metabolic process & & & 2.7E-07 & & $1 \mathrm{E}-10$ \\
\hline Organic ether metabolic process & & & & & 4.5E-11 \\
\hline Carboxylic acid catabolic process & $6.1 \mathrm{E}-11$ & 7.3E-07 & $2.8 \mathrm{E}-08$ & $1.9 \mathrm{E}-09$ & $6.1 \mathrm{E}-11$ \\
\hline Organic acid catabolic process & $6.1 \mathrm{E}-11$ & $7.3 \mathrm{E}-07$ & $2.8 \mathrm{E}-08$ & $1.9 \mathrm{E}-09$ & $6.1 \mathrm{E}-11$ \\
\hline Coenzyme metabolic process & $9.4 \mathrm{E}-13$ & & & $2 \mathrm{E}-07$ & 1.7E-10 \\
\hline Cofactor metabolic process & $1.6 \mathrm{E}-17$ & $3.0 \mathrm{E}-06$ & & $2.1 \mathrm{E}-07$ & $2 \mathrm{E}-11$ \\
\hline Fatty acid metabolic process & & & & & $1.8 \mathrm{E}-12$ \\
\hline Oxidation reduction & $1.7 \mathrm{E}-23$ & $1 \mathrm{E}-11$ & $1.4 \mathrm{E}-16$ & $6.1 \mathrm{E}-14$ & $3.4 \mathrm{E}-28$ \\
\hline Sterol homeostasis & & & $7.2 \mathrm{E}-08$ & & \\
\hline Cholesterol homeostasis & & & $7.2 \mathrm{E}-08$ & & \\
\hline Lipid homeostasis & & & & $4.8 \mathrm{E}-07$ & \\
\hline Lipid transport & & & & $2 \mathrm{E}-07$ & \\
\hline Hexose metabolic process & & & & $2.1 \mathrm{E}-07$ & \\
\hline Steroid metabolic process & & & $2.6 \mathrm{E}-11$ & $2 \mathrm{E}-08$ & \\
\hline Monosaccharide metabolic process & & & & $1.4 \mathrm{E}-07$ & \\
\hline Pyruvate metabolic process & & $1.3 \mathrm{E}-05$ & & & \\
\hline Acute-phase response & & $3.2 \mathrm{E}-05$ & & & \\
\hline Cellular carbohydrate biosynthetic process & & $5.9 \mathrm{E}-06$ & & & \\
\hline Acute inflammatory response & & $7.3 \mathrm{E}-07$ & & & \\
\hline Glucose metabolic process & & 0.00001 & & & \\
\hline Response to wounding & & $3.5 \mathrm{E}-07$ & & & \\
\hline Electron transport chain & 2.7E-10 & & & & \\
\hline ncRNA metabolic process & $4.2 \mathrm{E}-15$ & & $1.8 \mathrm{E}-09$ & & \\
\hline mRNA processing & $6.7 \mathrm{E}-16$ & & & & \\
\hline Translation & $7 E-16$ & & & & \\
\hline RNA processing & $8.8 \mathrm{E}-16$ & & & & \\
\hline
\end{tabular}

Numbers in the table represent the $p$ value given by DAVID. 
transport and regulate steroid and monosaccharide homeostasis. RXR $\alpha$-PXR targets specific biological processes like regulating pyruvate and carbohydrate biotransformation, but it also has a role in acute-phase response, acute inflammatory response, and response to wounding. Taken together, RXR $\alpha-\mathrm{RAR} \alpha$ targeted protein and RNA processes while RXR $\alpha-\mathrm{PXR} / \mathrm{LXR} / \mathrm{FXR} / \mathrm{PPAR} \alpha$ targeted homeostasis regulation of small molecules, which include monosaccharide and lipids.

\section{Global profiling of the expression of lipid homeostasis} genes in wild type and RXRa KO mice treated with and without RA

Hepatic RXR $\alpha$ KO mice have elevated serum cholesterol and triglyceride levels [21], and the majority of PXR, LXR, FXR, PPAR $\alpha$-bound genes were also bound by RXR $\alpha$. We next tested a hypothesis that RA and hepatic RXR $\alpha$ could regulate lipid homeostasis in the mouse liver via $\mathrm{RXR} \alpha$ and its heterodimeric partners. The expression levels of the lipid homeostasis genes (579) in the KEGG pathway database were studied in wild type and hepatic RXR $\alpha \mathrm{KO}$ mice treated with and without RA. The PCA score plot showed that RA treatment of wild type mice caused a downward shift in $\mathrm{C} 2$ from the untreated control group (Figure 3A). In contrast, an upward shift was found due to hepatic RXR $\alpha$ deficiency in comparison to the untreated wild type mice. Thus, RA treatment and RXR $\alpha$ deficiency had opposite effects. In addition, no significant change was noted when RA was used to treat hepatic RXR $\alpha$ KO mice. These findings unequivocally prove that the effects of RA on regulating those lipid homeostasis genes were RXR $\alpha$ dependent. Score plot (Figure 3A) indicates component 2 made a contribution to distinguish groups of control, RA-treated, and RXR $\alpha$-deficient mice. Thus, 114 out of 579 genes with high loading values $(>0.5$ or $<-0.5)$ in component 2 were selected for further analysis (Figure $3 \mathrm{~B}$ ). Among them, 55 genes were induced by RA and had decreased expression levels due to RXR $\alpha$ deficiency. The other 59 genes, whose expression levels were suppressed by RA, had increased expression levels due to a lack of RXR $\alpha$. Thus, the expression levels of those 114 lipidrelated genes are ligand (RA)-responsive and receptor $(\mathrm{RXR} \alpha)$-dependent. Based on the known function of those genes described in KEGG and PubMed, the role of those 114 genes was assigned and summarized in Table 2. Remarkably, RA regulated many genes involved in certain pathways. For example, RA decreased the expression of 10 genes in the cholesterol biosynthesis pathway, but did not increase the expression of any other genes in the same pathway. Thus, it is very likely that RA inhibited the biosynthesis of cholesterol in an RXR $\alpha$-dependent manner. RA also induced the expression of 13 genes in the RA elimination process and yet did not reduce the expression of any gene in the same process. Thus, RA can selfregulate its own level. Furthermore, RA also induced the expression of 9 genes in the biosynthesis of unsaturated fatty acids responsible for anti-inflammation. Since there was no inhibition of gene expression in the same pathway, it is very likely that RA up-regulates the synthesis of unsaturated fatty acids and has an anti-inflammatory role.
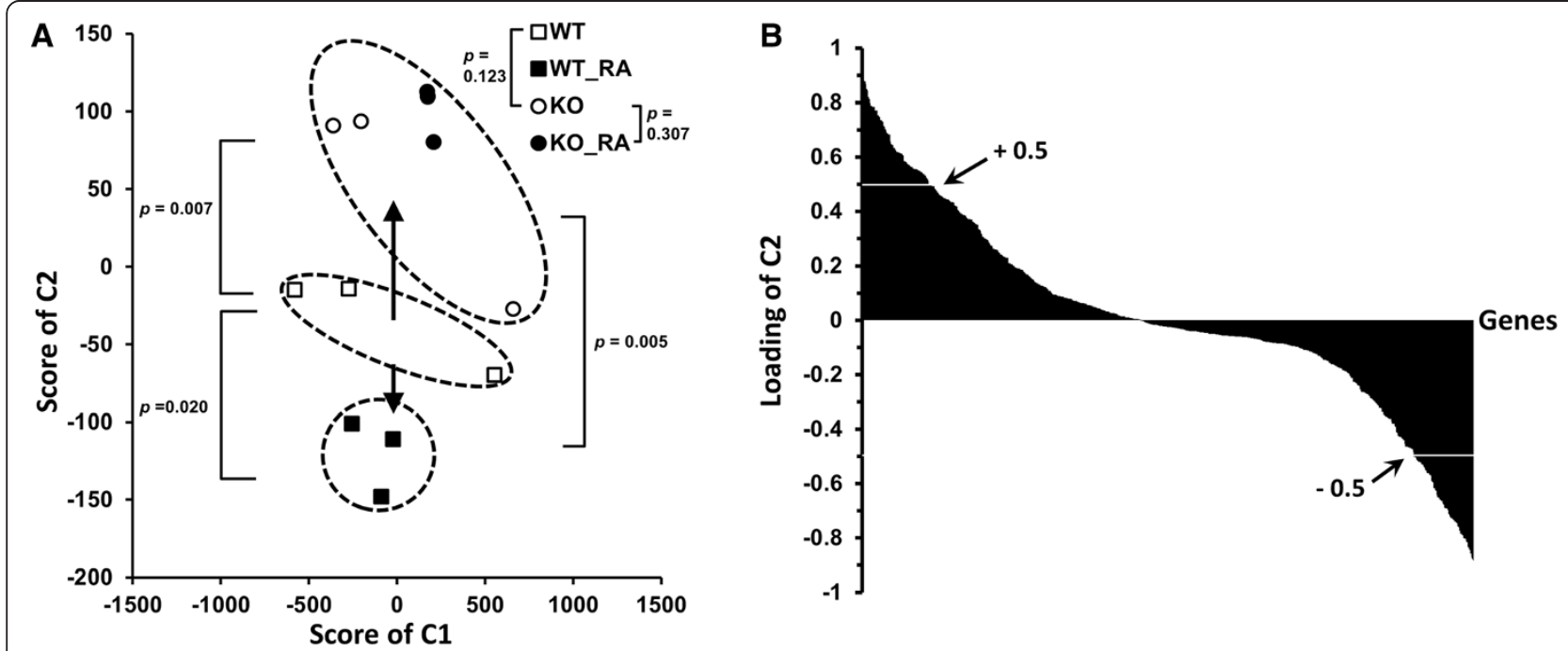

Figure 3 PCA of the expression level of 579 lipid genes in wild type and hepatic RXRa-KO mice treated with and without RA. Wild type and hepatic RXRa KO mice were treated with and without RA for 7 days ( $150 \mathrm{mg} / \mathrm{kg}$ diet, $\mathrm{n}=3$ ). The expression of $579 \mathrm{genes}$ involved lipid homeostasis was studied. (A) Score plot of PCA showing the difference among the groups. Spots within an ellipse belong to the same group. Arrows represent the direction separating groups from the wild type (WT) mice (open square $\square$ ). There is no significance in the C1component observed across all groups. (B) A histogram that shows the loading value of genes on C2. Genes with high loading value ( $\geq 0.5$ ) on C2 had higher mRNA levels in RXRa KO than wild type livers. In contrast, genes with low loading value $(\leq-0.5)$ on $\mathrm{C} 2$ had increased mRNA levels due to RA treatment. 
Table 2 Biological functions responding to RA treatment and RXRa knockout in wild type mice

\begin{tabular}{|c|c|c|c|c|}
\hline \multirow{3}{*}{$\begin{array}{l}\text { Biological functions } \\
\text { Lipid droplet growth }\end{array}$} & \multicolumn{4}{|c|}{$\begin{array}{c}\text { Gene number } \\
\text { (with RXRa bindings) }\end{array}$} \\
\hline & \multicolumn{2}{|c|}{$\begin{array}{l}\text { RA induced } \\
\text { \& RXRa KO } \\
\text { repressed }\end{array}$} & \multicolumn{2}{|c|}{$\begin{array}{l}\text { RA repressed } \\
\text { \& RXRa KO } \\
\text { induced }\end{array}$} \\
\hline & 1 & $(0)$ & 2 & $(2)$ \\
\hline $\begin{array}{l}\text { Transportation of bile aicds for bile } \\
\text { excretion }\end{array}$ & 1 & (0) & 0 & \\
\hline $\begin{array}{l}\text { Dehydrogenation of saturated fatty acids } \\
\text { to unsaturated fatty acids }\end{array}$ & 3 & $(2)$ & 0 & \\
\hline Biosynthesis of glycerol phosphalipids & 4 & (3) & 1 & $(1)$ \\
\hline Tryglyceride degration & 4 & (3) & 0 & \\
\hline $\begin{array}{l}\text { Biosynthesis of unsaturated fatty acids } \\
\text { responsible for aniti-inflammation }\end{array}$ & 9 & (7) & 0 & \\
\hline Elimination of retinoic acids & 13 & (11) & 0 & \\
\hline Biosynthesis of bile acids & 4 & $(4)$ & 4 & (4) \\
\hline Biosynthesis of retinoic acids & 1 & $(1)$ & 2 & $(2)$ \\
\hline Biosynthesis of saturated fatty acids & 5 & (5) & 10 & (10) \\
\hline Degradation of glycerol phosphalipids & 1 & $(1)$ & 4 & (4) \\
\hline Degradation of saturated fatty acids & 10 & (10) & 5 & (5) \\
\hline Elimination of steroid hormones & 3 & (3) & 5 & (5) \\
\hline Fat digestion and absorption & 3 & (3) & 7 & (7) \\
\hline $\begin{array}{l}\text { Lipid droplet breakdown } \\
\text { (fat mobilization) }\end{array}$ & 1 & (1) & 1 & (1) \\
\hline Recycle of bile acids via hepatic-intestine & 1 & $(1)$ & 3 & (3) \\
\hline S1P degradation & 1 & $(1)$ & 1 & (1) \\
\hline $\begin{array}{l}\text { Transportation of bile aicds for kidney } \\
\text { excretion }\end{array}$ & 2 & $(2)$ & 3 & (3) \\
\hline DHS1P degradation & 1 & $(1)$ & 0 & \\
\hline $\begin{array}{l}\text { Elimination of unsaturated fatty acids } \\
\text { (PGE2) responsible for lipolysis inhibition }\end{array}$ & 1 & $(1)$ & 0 & \\
\hline $\begin{array}{l}\text { phosphatidylcholine to } \\
\text { phosphatidylethanolamine }\end{array}$ & 1 & $(1)$ & 0 & \\
\hline Sphingolipid biosynthesis & 1 & $(1)$ & 0 & \\
\hline SPH (SM) degradation & 0 & & 1 & $(0)$ \\
\hline Biosynthesis of cholesterol & 0 & & 10 & $(10)$ \\
\hline Biosynthesis of steroid hormone & 0 & & 1 & (1) \\
\hline Biosynthesis of tryglycerides & 0 & & 1 & (1) \\
\hline $\begin{array}{l}\text { Biosynthesis of unsaturated fatty acids } \\
\text { responsible for pro-inflammation }\end{array}$ & 0 & & 1 & (1) \\
\hline $\begin{array}{l}\text { Breakdown of phosphalipid to form } \\
\text { unsaturated fatty acids }\end{array}$ & 0 & & 1 & (1) \\
\hline $\begin{array}{l}\text { Elimination of cholesterol (from } \\
\text { cyculation back to liver for catabolism) }\end{array}$ & 0 & & 1 & (1) \\
\hline $\begin{array}{l}\text { Elimination of cholesterol via steoid } \\
\text { hormone pathway }\end{array}$ & 0 & & 1 & (1) \\
\hline $\begin{array}{l}\text { Phosphatidylethanolamine to } \\
\text { phosphatidylcholine }\end{array}$ & 0 & & 1 & (1) \\
\hline
\end{tabular}

ChIP-Seq data indicated that most of the genes (87 out of 114) had RXR $\alpha$ binding implying direct gene regulation.

Taken together, ligand (RA) treatment and hepatic RXR $\alpha$ deficiency resulted in opposite effects. Figure 4 summarizes the effect of RA and hepatic RXR $\alpha$ deficiency on lipid homeostasis. RXR $\alpha$ deficiency tends to favor saturated fatty acids, triglyceride, cholesterol, and bile acids synthesis. In contrast, RA treatment leads to unsaturated fatty acids and phospholipid synthesis and lipolysis as well as triglyceride breakdown.

\section{Binding of RA/RXRa responsive genes by other nuclear receptors}

Additional analysis was done to understand which other nuclear receptors may be involved in regulating the expression of these 114 RA/RXR $\alpha$ target genes, which have a role in lipid homeostasis. The binding data generated in the current study (RXR $\alpha$ and RAR $\alpha$ ) were compared with the binding data of PXR, LXR, FXR, and PPAR $\alpha$. Figure 5 shows overlapping genes with $\mathrm{RXR} \alpha$-heterodimers, as assessed by overlapping binding of RXR $\alpha$ and other nuclear receptors. The data were organized by the number of different nuclear receptors binding the genes. For example, motifs located in the Abca1, Abhd5, Acsl, and Aldh3a2 genes could be bound by RXR $\alpha$ and all five nuclear receptors. Peaks located in the Apoa4, Cyp51, Cyp7b1, and Elovl1 could be bound by RXR $\alpha$ and any 4 out of the 5 studied nuclear receptors (Figure 5). Some of the commonly regulated genes have nuclear receptor binding site at the same location. The data indicated extensive crosstalk among nuclear receptors in regulating the expression of those genes.

\section{Quantification of serum cholesterol, triglyceride, and bile acid levels}

ChIP-Seq and RNA expression profiling indicate the role of RA in controlling lipid homeostasis in the liver. Serum cholesterol, triglyceride, and bile acid levels were quantified to test the genetic findings. The data showed that RA reduced serum cholesterol, triglyceride as well as bile acid levels in wild type mice (Figure 6). However, such effects were not found in hepatic RXR $\alpha \mathrm{KO}$ mice. In addition, serum cholesterol and triglyceride, but not bile acid, levels were elevated due to RXR $\alpha$ deficiency. These biochemical findings confirm the role of RA in regulating lipid homeostasis in the liver.

\section{Discussion}

This study establishes the role of nuclear receptors and RA in regulating lipid homeostasis in the liver. In addition, the mechanisms by which nuclear receptors and RA regulate lipid homeostasis were illustrated at the gene, pathway, and systemic levels. Furthermore, relationships between RXR $\alpha$ and PXR, LXR, FXR, as well as PPAR $\alpha$ in regulating lipid homeostasis were analyzed. These nuclear receptors depend 


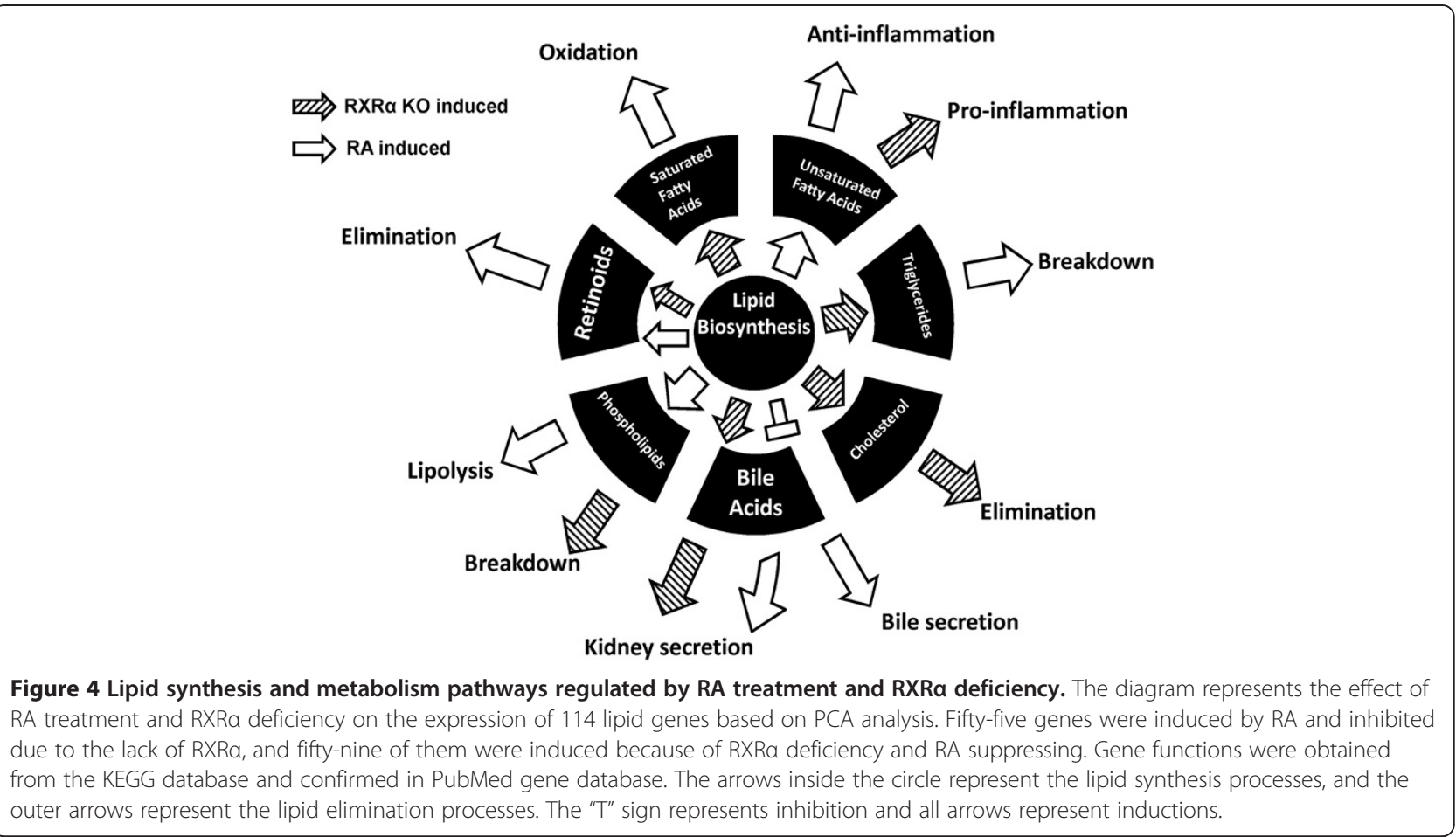

on RXR $\alpha$ to execute their functions and more than $85 \%$ of their bound genes overlap with those bound by RXR $\alpha$. The nuclear receptor binding data were strengthened by profiling the expression patterns of 576 lipid genes, which showed that RA treatment and RXR $\alpha$-deficiency had an opposite effect in regulating lipid homeostasis. Nuclear receptor binding data also illustrated extensive cross talk among the studied nuclear receptors. Thus, our novel in vivo data provided extensive evidence showing the role of RA in dictating lipid homeostasis in the liver.

It is intriguing that more than $85 \%$ of the PXR, LXR, FXR, and PPAR $\alpha$ binding sites overlapped with those of RXR $\alpha$. In contrast, only $43 \%$ of RAR $\alpha$ binding sites overlapped with those of RXR $\alpha$. It has been shown that RAR $\alpha$ can form homodimers [22]. It is also possible that RAR $\alpha$ may dimerize with RXR $\beta$ and RXR $\gamma$ to exert its function. Although the percentage of overlapping bindings between RAR $\alpha$ and RXR $\alpha$ is not as high as others, the number of genes that could be bound by $\operatorname{RXR} \alpha / \operatorname{RAR} \alpha$ (4554) is the highest, followed by RXR $\alpha / P P A R \alpha$ (3468), RXR $\alpha / F X R$

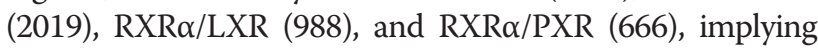
the relatively extensive role of these nuclear receptors in regulating hepatic gene expression. It is important to further study the role of RAR $\alpha$ and other RARs in the liver. By forming partners with other nuclear receptors, $\mathrm{RXR} \alpha$ is a master regulator. Our data showed that more than 8000 hepatic genes were bound by RXR $\alpha$, and $72 \%$ of them overlapped with the genes bound by RAR $\alpha$, PXR, LXR, FXR, or PPAR $\alpha$. The remaining $28 \%$ of RXR $\alpha$ binding sites might be bound by RXR $\alpha$ homodimer or the heterodimer of
RXR $\alpha$ and VDR or CAR. Thus, the five nuclear receptors (RAR $\alpha$, PXR, LXR, FXR, or PPAR $\alpha$ ) analyzed in the current study account for almost three quarters of RXR $\alpha$ binding genes in the liver. Furthermore, nearly $50 \%$ of RXR $\alpha$ bindings overlapped with the bindings of PXR, LXR, FXR, and PPAR $\alpha$ (Figure 1B). Hence, lipid regulation should be one of the major functions of RXR $\alpha$.

Clustering and PCA showed that the genome-wide binding pattern of RAR $\alpha$ is not similar to that of PPAR $\alpha$, LXR, PXR, and FXR. Biological function annotation also showed that RAR $\alpha$ has some unique features including protein processing, protein localization, and RNA processing. However, the five studied nuclear receptors also demonstrated functional redundancy. For example, there are four pathways, including oxidation reduction, carboxylic acid catabolic process, organic acid catabolic process, and cofactor metabolic process, that can be regulated by more than four nuclear receptors. This finding suggests the importance of these four pathways in the liver, and the role of RAR $\alpha$ in them.

Although PPAR $\alpha$, LXR, FXR, and PXR have extensive roles in regulating lipids, they also have specific roles in regulating different types of lipids. RXR $\alpha /$ PPAR $\alpha$ prefers to bind to genes that participate in neutral lipids, glycerol ether, and organic ether as well as fatty acid metabolism processes. All of which are either fatty acid-derived products or precursors for the biosynthesis of fatty acids. Another pathway bound by $\mathrm{RXR} \alpha / \mathrm{PPAR} \alpha$ is the acylglycerol metabolic process, which is involved in triglyceride homeostasis. RXR $\alpha / \mathrm{LXR}$ tends to regulate genes involved in sterol 

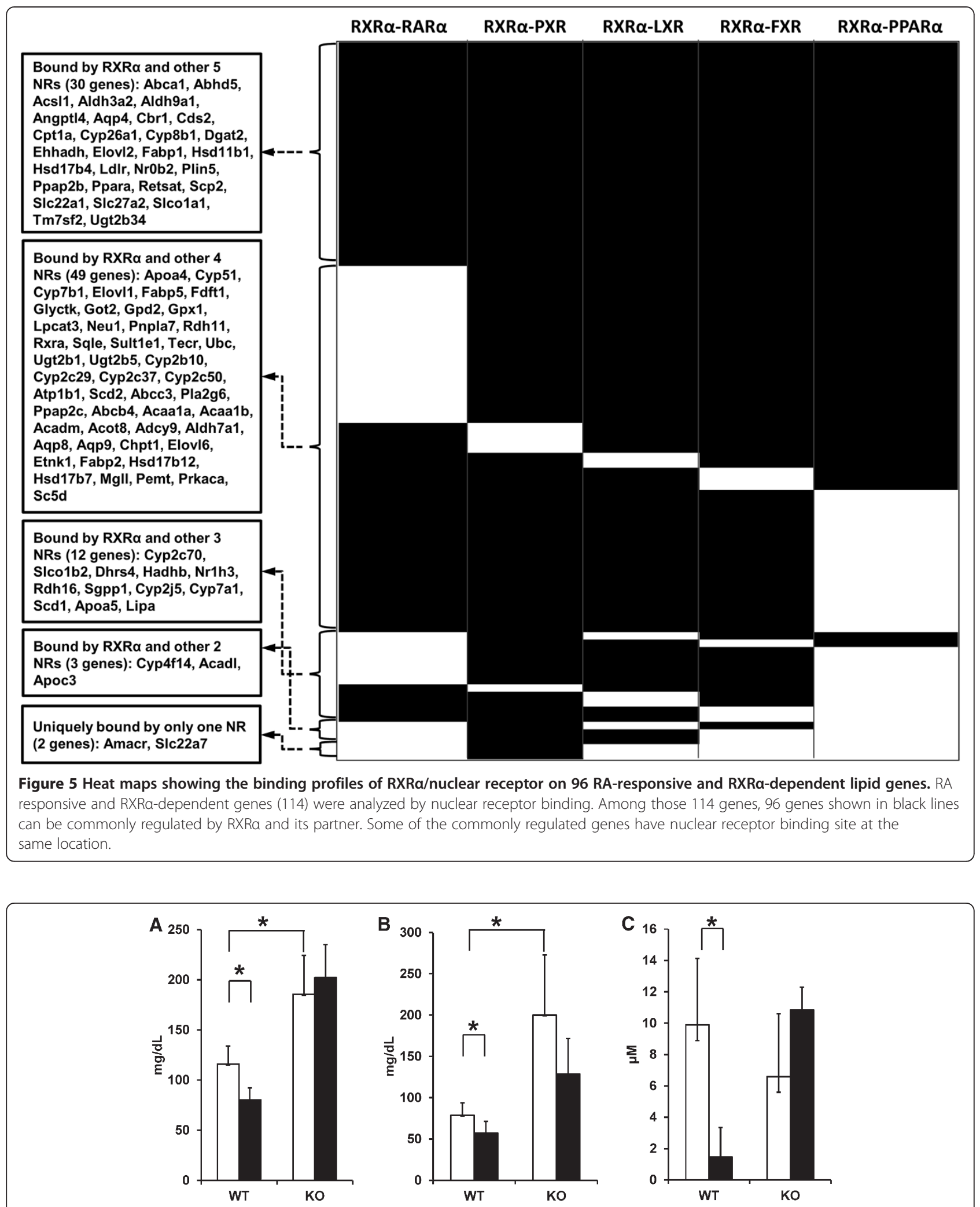

Figure 6 Serum cholesterol, triglyceride, and bile acid levels in wild type and hepatocyte RXRa KO mice treated with and without RA. Male wild type (WT) and hepatocyte RXRa KO (KO) mice were fed laboratory chow with (black bars) and without (white bars) all-trans RA

$(150 \mathrm{mg} / \mathrm{kg}$ diet) for 7 days $(n=6)$. Serum cholesterol $(\mathbf{A})$, triglyceride $(\mathbf{B})$, and bile acid $(\mathbf{C})$ levels were quantified at the end of the treatment. * $p<0.01$ 
metabolism, which is consistent with its known role [23]. RXR $\alpha / F X R$ not only binds to the genes participating in steroid metabolism process, but also those involved in lipid transport and carbohydrate metabolism processes. RXR $\alpha$ / PXR binds to the genes involved in regulating the pyruvate metabolic process at the DNA binding level. Pyruvate is a key intersection for fatty acid, carbohydrate, and protein metabolisms. In addition, $\mathrm{RXR} \alpha / \mathrm{PXR}$ also regulates response to acute phase, inflammatory, and wounding, implying that PXR can be an excellent target for metabolism and inflammation-related health issues. Lastly, FXR binds to the genes involved in monosaccharide metabolism, which shows the intimate relationship between bile acid and glucose homeostasis [24].

All of the 114 genes that showed differential effects of RA treatment and RXR $\alpha$ deficiency are bounded by RXR $\alpha$ and RAR $\alpha$, PXR, LXR, FXR, and PPAR $\alpha$ heterodimers. These findings indicate that those studied nuclear receptors retain RA response in vivo and the effect of RA is dependent upon those nuclear receptors. RA has a broad spectrum of effects including biosynthesis of retinoids, phospholipids, and unsaturated fatty acids. It also has a role in eliminating retinoids, oxidizing saturated fatty acids, and breaking down triglycerides. It seems that RA has extensive beneficial effects in maintaining the health of the liver. Specifically, RA induced the expression of Cyp2c37/ 38/50/54/70 and Cyp2j5. These genes encode enzymes involved in the generation of epoxyeicosatrienoic acids [25], which have anti-inflammatory effects [26]. In contrast, RXR $\alpha$ deficiency induces the gene expression of Cyp4f that is responsible for the generation of 20hydroxyeicosatetraenoic acid, a pro-inflammation molecule [25]. In addition, RA increases mRNA levels of cbr1(carbonyl reductase 1 ), which is responsible for transforming prostaglandin E2 to prostaglandin F2 $\alpha$. Prostaglandin E2 and F2 $\alpha$ have different effects in regulating lipid breakdown. Prostaglandin E2 is a lipolysis inhibitor [27]; whereas, prostaglandin F2 $\alpha$ has not been shown to have the same effect. Thus, the induction of cbr1 gene expression could be a mechanism by which RA induces lipolysis. RA also induces expression levels of gene encoding proteins for phospholipid biosynthesis, but RXR $\alpha$ deficiency increases the expression of the genes that have a role in the degradation of phospholipids. This finding suggests the potential role of RA in maintaining the normal structure of the cell membrane. Formation of the monolayer of lipoprotein or lipid droplet is one of the major ways that phospholipids regulate lipid metabolism [28]. Phosphatidylethanolamine (PE) and phosphatidylcholine (PC) are two important phospholipids that show different effects on lipid metabolism in humans and rodents. Lower PC/PE ratio induces steatosis or even steatohepatitis in humans
[29], however, PE has a greater effect than PC in reducing the cholesterol level in rodents [30]. Our data showed that RA induced the gene expression of ptdss 1 (phosphatidylserine synthase 1), which converts PC to PE. Consistently, the ptdss 1 gene expression is reduced due to hepatic RXR $\alpha$ deficiency. These gene expression levels and DNA binding data not only showed the underlying mechanism for RA in regulating liver gene expression, but also suggested the biochemical outcome.

\section{Conclusions}

Taken together, the differentiation and morphogenetic effect of RA is well known. However, the current study provides a comprehensive analysis of the role of RA in lipid homeostasis. All-trans RA is the most abundant retinoid that can be easily detected in the liver. Thus, RA is likely to act as a regulator to control hepatic lipid metabolism. Since the effect of RA is broad, it is important to develop specific retinoids in order to target specific pathways. Such efforts may allow us to identify compounds that can be used to treat or prevent metabolic syndromes and other lipid-related health issues.

\section{Methods}

\section{Materials and animal models}

Male wild type mice (12 weeks old) and hepatocyte RXR $\alpha$-deficient mice (KO) $[10,11]$, which have the same genetic background of $\mathrm{C} 57 \mathrm{BL} / 6$, were used. The RXR $\alpha$ $\mathrm{KO}$ mice were produced and characterized previously $[10,11]$. The LoxP sites were inserted into introns flanking the fourth exon of the $\mathrm{RXR} \alpha$ gene covering the DNA binding domain, which is deleted after crossing the floxed RXR $\alpha$ allele against a transgenic line in which cre recombinase is expressed under the control of the albumin promoter. The mutant mice express a truncated protein that has the intact ligand binding domain, but lacks the DNA binding domain. Animal protocols and procedures were approved by the Institutional Animal Care and Use Committee (IACUC) at the University of Kansas Medical Center and the University of California, Davis.

All ChIP-grade antibodies except anti-RNA Pol II (Millipore, MA) were purchased from Santa Cruz Biotechnology, Inc. (Santa Cruz, CA). DNA purification kit was purchased from Qiagen Co. (Valencia, CA). All other ChIPrelated reagents were obtained from Invitrogen Co. (Carlsbad, CA).

\section{Animal treatment}

Retinoic acid (Sigma-Aldrich, MO) was given to wild type and hepatic RXR $\alpha$-deficient mice at a dosage of $150 \mathrm{mg} / \mathrm{kg}$ diet for 7 days. As controls, mice were fed with normal diet. 


\section{Chromatin immunoprecipitation (ChIP)}

ChIP was performed according to our previously published study [31]. After fixation, the mouse livers were subjected to lysis with cell and nuclear lysis buffer. Sonication was used to fragment the chromatin, followed by precipitation with specified antibodies. The target DNA fragments were obtained by reverse crosslinking and purification. Antibodies against IgG and RNA Pol II were used as negative and positive controls, respectively.

\section{DNA library preparation and sequencing}

By using the End-It DNA End Repair Kit (Illumina, Madison, WI), DNA fragments prepared from ChIP were ligated with specified adaptors and amplified, then size-selected (175-225 bp) on an agarose gel followed by sequencing (High-Seq 2000, Illumina, Madison, WI).

\section{Alignment, call peak, and annotation of ChIP-seq data}

The target sequences were aligned to the mouse genome (http://hgdownload.cse.ucsc.edu/goldenPath/mm10/bigZips/) by Bowtie 0.12.7 [32] followed by peak-calling using MACS (version 1.4.1) [33]. The peaks were annotated using the database (NCBI37/mm9) by Peak Analyzer [34]. The background cut off standard was set to be 20 fold of the input signals [18]. The cut off distance from the transcription start site (TSS) was set to be $10 \mathrm{~kb}$. Co-localization is defined as having at least $25 \%$ overlap in their peak widths.

\section{Microarray}

Affymetrix 430 A 2 Chip (Santa Clara, CA) was used to determine the genome-wide mRNA expression levels. Microarray data were annotated using Affymetrix Expression Console (MAS5). The probe signal with $p$ values less than 0.05 were used for further analysis.

\section{ChIP-seq data analysis}

All data were treated with the same cut off criteria. The generated RXR $\alpha$ binding data were compared with the data for RAR $\alpha$, PXR, LXR, FXR, and PPAR $\alpha$. The principle component analysis (PCA) and cluster analysis package in SPSS program was used to analyze the global binding data. For both PCA and cluster analysis, called peaks were assigned the value of 1 . Not called peaks were assigned the value of 0 . Genes with overlapping binding sites of RXR $\alpha$ and each of RAR $\alpha$, PXR, LXR, FXR, and PPAR $\alpha$ at the same location were functionally analyzed by the DAVID (http://david.abcc.ncifcrf.gov/) [35].

\section{Lipid homeostasis analysis based on mRNA expression}

Genes (579) involved in regulating lipid homeostasis were extracted from the KEGG database (Kyoto Encyclopedia of Genes and Genomes, http://www.genome.jp/kegg/). The expression of those 579 genes were determined in wild type and liver RXR $\alpha \mathrm{KO}$ mice treated with and without
RA $(\mathrm{n}=3)$ for 7 days. After multiple comparisons, only 30 and 36 out of all 579 lipid homeostasis genes showed significant change at the corrected p-value of 0.05 after RA treatment and RXR $\alpha$ knockout, respectively. Therefore, IBM SPSS PCA package was used to differentiate groups based on the global expression pattern of all 579 lipid homeostasis genes.

\section{Serum lipid assays}

Triglyceride, cholesterol, and bile acids in the serum were assayed using a commercially available kit (Pointe Detroit, Michigan) that was modified to a 96-well format. Spectrophotometric analysis was conducted with a Bio-Tek microtiter plate reader (Bio-Tek, VT).

\section{Availability of supporting data}

The microarray and ChIP-Seq data supporting the results of this article are available with accession numbers of GSE50028 and GSE46762, respectively, in the GEO repository (http://www.ncbi.nlm.nih.gov/geo/).

\section{Abbreviation \\ RA: Retinoic acid; ChIP: Chromatin immunoprecipitation; seq: Sequencing; RXRa: Retinoid $x$ receptor alpha; RARa: Retinoic acid receptor alpha; PXR: Pregnane x receptor; LXR: Liver x receptor; FXR: Farnesoid x receptor; PPARa: Peroxisome proliferator-activated receptor alpha; DAVID: Database for annotation, visualization and integrated discovery; PCA: Principal component analysis; WT: Wild type; KO: Knockout; NR: Nuclear receptors; KEGG: Kyoto encyclopedia of Genes and genomes; PE: Phosphatidylethanolamine; PC: Phosphatidylcholine.}

\section{Competing interests}

The authors declare that they have no competing interests.

\section{Authors' contributions}

YH: Performed experiments, analyzed data, generated figures and tables as well as prepared manuscript. LG: Microarray experiments and analysis. YF: Sequence alignment and call peaks. QZ: Functional annotation. H-XL: Animal experiments. YL: Statistics analysis. GLG: FXR ChIP Seq data generation. LL-M: Microarray data generation. JF: Sequence alignment and call peaks. Y-JYW: Generated idea and supervised the all overall performance of the project. All authors read and approved the final manuscript.

\section{Acknowledgements}

The authors thank Dr. Stan Svojanovsky for his assistance in microarray data processing. We also thank Dr. Sidhartha Hazari, Ms. Julia Ann Wu, and Ms.

Jessica Tsuei for editing the manuscript, and Drs. Ann Thomas, Yue Cui and Le Zhan for sharing with us the technique of ChIP assay and the methodology of data analysis.

\section{Author details}

${ }^{1}$ Department of Medical Pathology and Laboratory Medicine, University of California, Davis Health Systems, Sacramento 95817, CA, USA. ²Discovery Toxicology, Bristol-Myers Squibb Company, Princeton 08543, NJ, USA.

${ }^{3}$ Applied Bioinformatics Laboratory, University of Kansas, Lawrence, KS, USA.

${ }^{4}$ Department of Gastroenterology Hepatology, First Municipal People's Hospital of Guangzhou, Guangzhou Medical College, Guangzhou 510180, China. ${ }^{5}$ Department of Pharmacology and Toxicology, Ernest Mario School of Pharmacy, Rutgers University, Piscataway 08854, NJ, USA. ${ }^{6}$ Biometric Research Branch, National Cancer Institute, 9609 Medical Center Dr. Rockville, Rockville 20850, MD, USA.

Received: 22 March 2013 Accepted: 17 August 2013

Published: 28 August 2013 


\section{References}

1. Blomhoff R, Blomhoff HK: Overview of retinoid metabolism and function. J Neurobiol 2006, 66:606-630

2. Bushue N, Wan YJ: Retinoid pathway and cancer therapeutics. Adv Drug Deliv Rev 2010, 62:1285-1298.

3. Mukherjee R, Strasser J, Jow L, Hoener P, Paterniti JR Jr, Heyman RA: RXR agonists activate PPARalpha-inducible genes, lower triglycerides, and raise HDL levels in vivo. Arterioscler Thromb Vasc Biol 1998, 18:272-276.

4. Willy PJ, Umesono K, Ong ES, Evans RM, Heyman RA, Mangelsdorf DJ: LXR, a nuclear receptor that defines a distinct retinoid response pathway. Genes Dev 1995, 9:1033-1045.

5. Urizar NL, Dowhan DH, Moore DD: The farnesoid X-activated receptor mediates bile acid activation of phospholipid transfer protein gene expression. J Biol Chem 2000, 275:39313-39317.

6. Lemay DG, Hwang DH: Genome-wide identification of peroxisome proliferator response elements using integrated computational genomics. J Lipid Res 2006, 47:1583-1587.

7. Wang $K_{1}$ Chen S, Xie W, Wan YJ: Retinoids induce cytochrome P450 3A4 through RXR/VDR-mediated pathway. Biochem Pharmacol 2008, 75:2204-2213.

8. Chen S, Wang K, Wan YJ: Retinoids activate RXR/CAR-mediated pathway and induce CYP3A. Biochem Pharmacol 2010, 79:270-276.

9. Wan YJ: Retinoic acid and its receptors. Am J Surg 1993, 166:50-53.

10. Wan YJ, An D, Cai Y, Repa JJ, Hung-Po Chen T, Flores M, Postic C, Magnuson MA, Chen J, Chien KR et al: Hepatocyte-specific mutation establishes retinoid $\mathrm{X}$ receptor alpha as a heterodimeric integrator of multiple physiological processes in the liver. Mol Cell Biol 2000, 20:4436-4444.

11. Wan YJ, Cai Y, Lungo W, Fu P, Locker J, French S, Sucov HM: Peroxisome proliferator-activated receptor alpha-mediated pathways are altered in hepatocyte-specific retinoid $\mathrm{X}$ receptor alpha-deficient mice. J Bio/ Chem 2000, 275:28285-28290.

12. Gyamfi MA, He L, French SW, Damjanov I, Wan YJ: Hepatocyte retinoid X receptor alpha-dependent regulation of lipid homeostasis and inflammatory cytokine expression contributes to alcohol-induced liver injury. J Pharmacol Exp Ther 2008, 324:443-453.

13. Gyamfi MA, Tanaka Y, He L, Klaassen CD, Wan YJ: Hepatic effects of a methionine-choline-deficient diet in hepatocyte RXRalpha-null mice. Toxicol Appl Pharmacol 2009, 234:166-178.

14. Cai Y, Konishi T, Han G, Campwala KH, French SW, Wan YJ: The role of hepatocyte RXR alpha in xenobiotic-sensing nuclear receptor-mediated pathways. Eur J Pharm Sci 2002, 15:89-96.

15. Dai G, Chou N, He L, Gyamfi MA, Mendy AJ, Slitt AL, Klaassen CD, Wan YJ: Retinoid $X$ receptor alpha Regulates the expression of glutathione stransferase genes and modulates acetaminophen-glutathione conjugation in mouse liver. Mol Pharmacol 2005, 68:1590-1596.

16. Gyamfi MA, Kocsis MG, He L, Dai G, Mendy AJ, Wan YJ: The role of retinoid $X$ receptor alpha in regulating alcohol metabolism. J Pharmacol Exp Ther 2006, 319:360-368.

17. Wan YJ, Han G, Cai Y, Dai T, Konishi T, Leng AS: Hepatocyte retinoid X receptor-alpha-deficient mice have reduced food intake, increased body weight, and improved glucose tolerance. Endocrinology 2003, 144:605-611.

18. Cui JY, Gunewardena SS, Rockwell CE, Klaassen CD: ChIPing the cistrome of PXR in mouse liver. Nucleic Acids Res 2010, 38:7943-7963.

19. Boergesen M, Pedersen TA, Gross B, Van Heeringen SJ, Hagenbeek D, Bindesboll C, Caron S, Lalloyer F, Steffensen KR, Nebb Hl et al: GenomeWide Profiling of Liver X Receptor, Retinoid X Receptor, and Peroxisome Proliferator-Activated Receptor alpha in Mouse Liver Reveals Extensive Sharing of Binding Sites. Mol Cell Biol 2012, 32:852-867.

20. Thomas AM, Hart SN, Kong B, Fang J, Zhong XB, Guo GL: Genome-wide tissue-specific farnesoid $X$ receptor binding in mouse liver and intestine. Hepatology 2010, 51:1410-1419.

21. Wan YJ, An D, Cai Y, Repa JJ, Hung-Po Chen T, Flores M, Postic C, Magnuson MA, Chen J, Chien KR et al: Hepatocyte-specific mutation establishes retinoid $\mathrm{X}$ receptor alpha as a heterodimeric integrator of multiple physiological processes in the liver. Mol Cell Biol 2000, 20:4436-4444.

22. Mader S, Chen JY, Chen Z, White J, Chambon P, Gronemeyer $\mathrm{H}$ : The patterns of binding of RAR, RXR and TR homo- and heterodimers to direct repeats are dictated by the binding specificites of the DNA binding domains. EMBO J 1993, 12:5029-5041.

23. Repa JJ, Liang G, Ou J, Bashmakov Y, Lobaccaro JM, Shimomura I, Shan B, Brown MS, Goldstein JL, Mangelsdorf DJ: Regulation of mouse sterol regulatory element-binding protein-1c gene (SREBP-1c) by oxysterol receptors, LXRalpha and LXRbeta. Genes Dev 2000, 14:2819-2830.

24. Duran-Sandoval D, Mautino G, Martin G, Percevault F, Barbier O, Fruchart JC, Kuipers F, Staels B: Glucose regulates the expression of the farnesoid X receptor in liver. Diabetes 2004, 53:890-898

25. Theken KN, Deng Y, Kannon MA, Miller TM, Poloyac SM, Lee CR: Activation of the acute inflammatory response alters cytochrome P450 expression and eicosanoid metabolism. Drug Metab Dispos 2011, 39:22-29.

26. Node K, Huo Y, Ruan X, Yang B, Spiecker M, Ley K, Zeldin DC, Liao JK: Antiinflammatory properties of cytochrome P450 epoxygenase-derived eicosanoids. Science 1999, 285:1276-1279.

27. Henkel J, Frede K, Schanze N, Vogel H, Schurmann A, Spruss A, Bergheim I, Puschel GP: Stimulation of fat accumulation in hepatocytes by PGE(2)dependent repression of hepatic lipolysis, beta-oxidation and VLDLsynthesis. Lab Invest 2012.

28. Zeisel SH: Choline: needed for normal development of memory. J Am Coll Nutr 2000, 19:528S-531S

29. Li Z, Agellon LB, Allen TM, Umeda M, Jewell L, Mason A, Vance DE: The ratio of phosphatidylcholine to phosphatidylethanolamine influences membrane integrity and steatohepatitis. Cell Metab 2006, 3:321-331.

30. Imaizumi K, Mawatari K, Murata M, Ikeda I, Sugano M: The contrasting effect of dietary phosphatidylethanolamine and phosphatidylcholine on serum lipoproteins and liver lipids in rats. J Nutr 1983, 113:2403-2411.

31. Zhan Q, Fang Y, He Y, Liu H-X, Fang J, Wan Y-JY: Function annotation of hepatic retinoid $x$ receptor a based on genome-wide DNA binding and transcriptome profiling. PLOS one 2012, 7:e50013.

32. Langmead B, Trapnell C, Pop M, Salzberg SL: Ultrafast and memoryefficient alignment of short DNA sequences to the human genome. Genome Biol 2009, 10:R25.

33. Zhang Y, Liu T, Meyer CA, Eeckhoute J, Johnson DS, Bernstein BE, Nusbaum C, Myers RM, Brown M, Li W, Liu XS: Model-based analysis of ChIP-Seq (MACS). Genome Biol 2008, 9:R137.

34. Salmon-Divon M, Dvinge $H$, Tammoja K, Bertone P: PeakAnalyzer: genomewide annotation of chromatin binding and modification loci. BMC Bioinforma 2010, 11:415.

35. Da Huang W, Sherman BT, Lempicki RA: Systematic and integrative analysis of large gene lists using DAVID bioinformatics resources. Nat Protoc 2009, 4:44-57.

doi:10.1186/1471-2164-14-575

Cite this article as: He et al:: The role of retinoic acid in hepatic lipid homeostasis defined by genomic binding and transcriptome profiling. BMC Genomics 2013 14:575.

\section{Submit your next manuscript to BioMed Central and take full advantage of:}

- Convenient online submission

- Thorough peer review

- No space constraints or color figure charges

- Immediate publication on acceptance

- Inclusion in PubMed, CAS, Scopus and Google Scholar

- Research which is freely available for redistribution 